\title{
The Determinant Factors that Influence Customers' Behavioral Intention in Property
}

\author{
Nurhazirah Hashim ${ }^{1}$, Ahasanul Haque ${ }^{2}$, Nur Hasyimah Hasim ${ }^{1,2}$ \\ ${ }^{1}$ Lecturer, \\ Universiti Teknologi MARA, 42300 Selangor, Malaysia \\ 2 Professor, \\ International Islamic University Malaysia, 50728 Kuala Lumpur, Malaysia \\ nurhazirah@puncakalam.uitm.edu.my
}

\begin{abstract}
The property industry acts as vital sector whereby the service environment directly correlates the customers' behavioral intention in purchasing a property. However, to date, a study regarding service environment and its impact still not fully addressed in the property industry. Thus, the purpose of this study is to investigate the relationship between service environment and customers' behavioral intention moderated by income in Malaysian property industry. A total of 357 respondents were participated in this study by using a convenience sampling. The result shown that lower middle income was significantly moderated the relationship between service environment and customers' behavioral intention.
\end{abstract}

Keywords: Service Environment; Customer's Behavioral Intention; Property Industry; Malaysia

Keywords: Standardization; bill of quantities (BQ); contract document; standard method of measurement (SMM)

eISSN 2398-4295 @ 2018 . The Authors. Published for AMER ABRA cE-Bs by e-International Publishing House, Ltd., UK. This is an open-access article under the CC BY-NC-ND license (http://creativecommons.org/licenses/bync-nd/4.0/). Peer-review under responsibility of AMER (Association of Malaysian Environment-Behaviour Researchers), ABRA (Association of Behavioural Researchers on Asians) and cE-Bs (Centre for EnvironmentBehaviour Studies), Faculty of Architecture, Planning \& Surveying, Universiti Teknologi MARA, Malaysia.

DOI: http://dx.doi.org/10.21834/ajbes.v3i12.132 


\subsection{Introduction}

The efficiency and effectiveness of the housing delivery system have been identified as major social and economic objectives in Malaysia. However, there is a massive problem of constructing housing in the country (Tan, 2008). Besides, according to Zainal (2010), the property industries are an important sector to Malaysian economy and has been classified that the housing development acts as a vital factors whereby the service environment directly correlate the customers' behavioral intention in purchasing a property. Furthermore, as stated by Tan (2008), the issues regarding the oversupply in the housing industry becomes the crucial concern of the government itself whereby lots of property units still remain unsold for the reasons of the price factor which is in the range from poor location to unattractive houses with inadequate features and facilities. This is due to different householders have different motivations of owning homes.

Furthermore, there are numerous studies that shown the internal responses affected the customers' behavioral intentions of the actors either approach and avoidance behavior. Approach behaviors like affiliation, exploration or staying longer and avoidance behavior which is the opposite of approach behavior and the social interactions between actors. As indicated in the studies, there are various empirical studies have been conducted which focusing on one or several variables of the service environment such as music, scent or signage and their effects on the consumer expenditures (Morrin and Che'bat, 2007; Che'bat and Michon, 2003), perceived waiting time (Bailey and Areni, 2006), loyalty intentions (Harris and Ezeh, 2008), or perceived quality (Reimer and Kuehn, 2005). All these variables have been explored in various literature reviews (Ezeh and Harris, 2007; Garlin and Owen, 2006; Turley and Milliman, 2000; Kearney, Kennedy and Coughlan, 2007).

From the literature in various fields, researchers have identified that the reactions of the customer towards the physical environment are directly related to their emotional states, mostly in the situation of hedonic consumption and it can influence one's emotion that will lead to behavioral intention either approach or avoidance behavior (Wirtz, Matilla and Tan, 2007; Newman, 2007; Ryu and Jang, 2007; Lucas and Santos, 2003 and Wakefield and Blodgett, 1996). According to Zainal (2010) the property industries are an important sector to the Malaysian economy. It has been classified that the housing development acts as a vital factors whereby the service environment directly correlate the customers' behavioral intention in purchasing a property. In addition, customers may feel grateful to a firm for its extra effort and favors, and reciprocate the favor by purchasing the organizations products or services (Morales, 2005). Moreover, Liu and Jang (2009) emphasized service environment as important for the researcher to deeply explore in order to determine the influences to the customers' behavioral intention. It can enhance the responsiveness of the property industry towards the individual responses of purchasing property.

In contrast, as stated by Liu and Jang (2009), other possible factors can be determined the relationship between the atmospherics and customers' behavioral intention such as familiarity, demographic information, and situational factors that brings further understanding towards the relationship. Other than that, Hyun and Lee (2011) also recommended that future research should have an attempt to further verify or extend the model with another locations which is other than United States sample to get more significant results of service 
environment and customers' behavioral intention. Therefore, this study is conducted to investigate the relationship between service environment and customers' behavioral intention moderated by income in Klang Valley property industry.

\subsection{Literature Review}

The largest investment that an individual or a family will make is purchasing a house for their family or themselves. So, due to the largest investment in property markets made by the purchaser, property companies or agents are strictly advisable to avoid any unethical behavior that will bring to the interest in a financial commission as well. This behavior can directly affect the customer's future intentions of doing business with the organization (Tuzovic, 2008). Moreover, the emphasis on improving the provision of housing by the government in Malaysia, housing is still a controversial issues in Malaysia. The issues concerning housing in Malaysia has changed from merely accessibility to affordability and quality of housing.

\subsection{Customer's Behavioral Intention}

In current studies, behavioral intention is among one of the main concepts in various marketing literature. The interests of marketing researchers on behavioral intention come from the relationship with the buying behavior (Hafedh and Faouzi, 2008). Besides, the exploration of the terms behavioral intention are usually discovered within the cognitiveaffective-conative structure (Lam, Shankar, Eramilli, and Murthy, 2004; Oliver, 1999) which has been justified by the self-regulatory mechanism model that has been tested by Bagozzi (1992). In contrast, the attribute appraisal which contains in the cognitive component is generally leads customer emotional responses. This component is eventually leaded to behavioral intention (Chiou and Droge, 2006). Besides, Luo and Homburg (2007) stated that the concept of behavioral intention was operationalized with four items. It is affecting to the customers loyalty, commitment and repurchase intentions and recommendations as well. The similarity measurement also used in the study conducted by Zeithaml, Berry, and Parasuraman (1996), Baker and Crompton (2000), and Brown, Broderick and Lee (2007).

Moreover, according to Kim and Moon (2009) by referring to the Mehrabian-Russel model, the stimulation regarding the response of human in terms of physical environment is divided into three parts. There are environmental stimuli, emotional states, and two opposite responses which is customers' behavioral intention that can be categorized as approach or avoidance behavior. Besides, Kim and Moon (2009) also mentioned that the environment itself generates an emotional response in individuals that can cause customers' behavioral intention either approach or avoidance behavior. Indeed, the Mehrabian-Russel model which integrates the perceptions of the physical environment, emotions, and response, is used as a theoretical foundation for the current study. Furthermore, based on the service environment studies, numerous environmental psychologists also recommend that people's feelings or emotions can bring what they do and how they do it (Donovan and Rossiter, 1982; Mehrabian and Russell, 1974).

Referring to Donovan and Rossiter (1982) and Turley and Milliman (2000), the relationship between service environment (servicescape) and customer behavior has been 
investigated in many different setting by landscapers, architects, interior designers, retailers, and environmental psychologists. From the studies, theoretical and empirical data from environmental psychology research also recommended that customer reactions to the physical environment which is also known as 'atmospherics' or 'service environment' can be determined as emotional than cognitive when hedonic preferences is involved. When customers are positive or negative with their emotion, they will lead to approach or avoidance behavior. In addition, as stated by Mano and Oliver (1993) and Russell and Pratt (1980) the level of pleasure for example unhappy and happy and arousal like excited or calm that customers experience during hedonic consumption may be a major determinant of their satisfaction and subsequent behavior such as repatronage and positive word-of-mouth. Overall, the existing of the research supports the concept of customers as environmental stimuli conducted in service environment's social dimension and expressively influenced other customers' approach or avoidance decisions and social interaction in a service formation. Customer environmental stimuli may represent the attraction that bond together with other customers to a service environment and it is important and outside the managerial control. Customers who frequently visiting a service firm, mostly to fulfill their consumption needs for goods and services are referring to their approach or avoidance behaviors on a firm's physical dimensions. In contrast with customers who visiting the organization because of the relationship needs should also respond to a firm's social and symbolically social service environment (Rosenbaum and Massiah, 2011).

\subsection{Service Environment}

According to Bitner (1992) service environment can be defined as built environment or in another term as a man-made, physical surroundings as contrasting to the natural or social environment which can affect the physical factors that have been developed by the service provider in order to enhance customer and employee behaviors. There are three principal dimensions of the service environment that have been identified that influenced customer perception of the service provider and the customers' responses. The dimensions are ambient conditions, spatial layout and functionality and signs, symbols, and artifacts as well. In addition, according to Bitner (1992), the dimension of ambient conditions such as temperature, noise, music, and lighting are directly refers to the physical features for example the surrounding of the external environment, the design of architecture, cleanliness and other physical elements in which customers can directly view and evaluate the quality of the service environment. Next dimension of service environment is spatial layout and functionality. Furthermore, Bitner (1992) also described the ways such as seats, hallways and walkways, foodservice lines, restrooms, and also the entrance and exits whereby they have been designed and logically arranged in the service settings. Third dimension is signs, symbols, and artifacts which are involving the decoration and the signage of the service setting that have been provided by the service provider to communicate and enhance the image or mood in order to attract the customers to the desired destinations.

On the other hand, in order to support the use of atmospherics or environmental of the service setting as a marketing enhancement, service environment can be defined as the conscious designing of space to enable the providers to produce particular emotional effects 
in the customers due to increase the customers option in purchasing. In contrast, service environment is delivered through the senses of the customers which can stimuli the surrounding. Physical stimuli in the atmosphere can be in terms of sight, sound, scent and taste (Kotler, 1973). Based on Kim and Moon (2009) the determination of the service environment dimensions that has been categorized by Bitner (1992) has three categories, it is not impossible if the results of each study regarding service environment can be in different results. This is due to the differentiation of the entire physical environment which includes the physical factors and the particular context that is varying among the types of service provided.

\subsection{The Link between Income, Service Environment and Customers' Behavioral Intention}

For most individuals, housing is the largest consumption and investment item of their lifetime and, as a result, housing satisfaction is an important component of their quality of life. According to the previous study, housing purchasing trend in Malaysia is determined by demographic profiles, mainly by education level, age, gender and income. The period of housing ownership also influences the socio-cultural interactions and satisfaction of house owners with their neighbourhoods (Salfarina, Malina and Azrina, 2010). Meeting housing needs for all has long been an objective of national policy in Malaysia. As a result, housing policies and programs are developed and implemented to increase the homeownership rate in the country, particularly the low-income group. Furthermore, the qualities of the environment are whereby the house buyers would take a consideration before buying a house, and these elements are significantly reflected in the property prices (Tan, 2011). On the other hand, good environmental elements carry significance property values. There are many studies conducted in Europe, Asia and the United States of America which have been evaluated the impacts of the qualities of environment, such as green space delivery (Tyrvainen, 1997; Tyrvainen and Mitettinen, 2000; Tajima, 2003; Jim and Chen, 2006), closeness to parks (Bolitzer and Netusil, 2000; Poudyal, Hodges and Merret, 2009) and views of green space and water (Luttik, 2000; Jim and Chen, 2006) on the price of houses. In addition, recently customers are more interested in living in a lively experienced environment rather than structures and patterns (Hanan, H., 2012). However, urban house owners prefer stylistic design for the house renovation instead of traditional design (Saruwono, M. et. al., 2012). Further, Syed Othman Thani, S.K., et. al. (2013) suggested property developer and urban property designer should consider a sustainable landscape design in order to improve a better quality of life.

Meanwhile, housing satisfaction is recognized as important component of home owners' general quality of life that lead to their individual behavioral intention and the degree to which home owners' needs and aspirations are met by their housing conditions is a concern for housing developers (Tan, 2011). As stated by Amole (2009), an empirical studies have been identified numerous number of important households' socio-demographic determinants of housing satisfaction, such as age, educational attainment, income, and life cycle changes whereby income plays a significant role for the individual to purchase a house and directly lead to the satisfaction of the development made by the developer. In addition, previous researcher also indicated that higher income households are generally satisfied with their 
housing conditions and neighborhood (Vera-Toscano and Alteca-Amestoy, 2008). By supporting with the other studies, it is clearly mentioned that instead of income, the evaluation of the physical characteristics, facilities, services and environment, whereas subjective measures refer to perception, emotions, attitudes, and also behavioral intention towards the housing attributes lead an individual in making choice (Mohit et al., 2009).

\subsection{Methodology}

The sample for this study was the potential customers at Glomac Property Berhad and Sime Darby Propety Berhad (2013). The sampling frame used in this study is obtained from the marketing and sales department from both organizations through a telephone call. However, the respective person only gives the researcher the estimation number of their customers per year due to all purchasers' information is confidential. Since it is quite impossible to obtain a complete list of the customers at selected property industries in Klang Valley, non-probability sampling was used which is convenience sampling technique and total numbers of 357 questionnaires were distributed. The data collected in the study was analyzed by using the Statistical Package for Social Sciences (SPSS) version 21.0. The analysis includes descriptive statistics such as frequencies, percentages, standard deviation, and means.

\subsection{Results and Discussion}

The questionnaire was distributed by the researcher personally by hand to the 357 respondents at chosen property industry in Klang Valley. A total of 357 questionnaires were personally distributed to potential customers in Klang Valley property industries namely Glomac Property Berhad and Sime Darby Property Berhad and no missing questionnaires were found. Therefore, the survey return rate of the collected questionnaire was $100 \%$ which the $(n=357)$.

There are six questions in the respondents' demographic background section and all data has been analyzed and interpreted by using the frequency and percentage. Based on the results in Table 4.1, it shows that a majority 187 of the respondents are female $(52.4 \%)$ while $170(47.6 \%)$ of the respondents are male. So, it can be concluded that the female respondents was absolutely higher as compared to the male respondents. Meanwhile, respondents who have answered the distributed questionnaire consisted of respondents' age under 30-34 years old which represents 32.5 percent of the total population. Then it follows by those respondents under the age of 35-39 years old which is 31.9 percent. Respondents under 25-29 years and 40 years and above contribute to the same percent which is 16.0 percent. Lastly, it follows by the respondents aged 20-24 years old that only represents 3.6 percent out of 357 respondents.

Besides, the majority of the respondents had a Bachelor Degree depicts 51.3 percent (183 respondents) while respondents with Diploma qualifications is 29.7 percent (106 respondents) and then respondents with Master qualification is 12.9 percent (46 respondents). Then, the remaining respondents are from SPM qualification represents only 6.2 percent (22 respondents) from the total number of respondents. Then, the majority of the 
respondents earn about RM3001-RM4001 with 42.6 percent (152 respondents) of the total number of respondents followed by the RM5001-RM7001 which represents 37.0 percent (132 respondents). In addition, income about RM1000-RM3000 only indicates 10.9 percent (39 respondents) and then the rest from the other income which is RM9001 an above illustrates 0.6 percent with two respondents from the total number of 357 respondents. On the other hand, the results also describes the most of the respondents are from nonexecutives level which depicts 53.2 percent (190 respondents) from the total 357 respondents. Then, followed by the respondents from executives level which represents 46.8 percent (167 respondents). Besides, by referring to the table above, it shows that 57.7 percent of the respondents from the private sector (206 respondents) while 151 respondents represent 42.3 percent from the government sector.

Table 4.1: Respondent's profile

\begin{tabular}{llcc}
\hline & & Frequency & Percentage \\
\hline Gender & Male & 170 & 47.6 \\
& Female & 187 & 52.4 \\
\hline Educational level & SPM & 22 & 6.2 \\
& Diploma & 106 & 29.7 \\
& Bachelor Degree & 183 & 51.3 \\
& Master Degree & 46 & 12.9 \\
\hline Position & Executive & 167 & 46.8 \\
& Non-Executive & 190 & 53.2 \\
\hline Income & RM1000-RM3000 & 39 & 10.9 \\
& RM3001-RM5000 & 152 & 42.6 \\
& RM5001-RM7000 & 132 & 37.0 \\
& RM7001-RM9000 & 32 & 9.0 \\
& RM9001 and above & 2 & 0.6 \\
\hline Age & $20-24$ years old & 13 & 3.6 \\
& $25-29$ years old & 57 & 16.0 \\
& $30-34$ years old & 116 & 32.5 \\
& $35-39$ years old & 114 & 31.9 \\
& 40 years old and above & 57 & 16.0 \\
\hline Sector & Government & 151 & 42.3 \\
& Private & 206 & 57.7 \\
\hline
\end{tabular}

\subsection{Correlation Analysis}

Based on the Table 4.2, the finding shows there is positive medium significant relationship between ambient conditions and customers' behavioral intention $(r=.309, p<0.05)$ which indicated that the dimension of service environment; ambient conditions is related to the customers' behavioral intention. It was supported by Robinson and Callan (2005) described the ambient conditions is positively correlates with the service environment due to the perception of the customers' directly influence the purchasing intention of the customers. Besides, the relationship between spatial, layout and functionality and customers' behavioral intention indicated that there is a positive medium significant relationship between two variables $(r=.358, p<0.05)$. As mentioned by Crouch and Louviere (2004) and Whitfield (2010), spatial, layout and functionality acts as an important factor to service environment and it is positively influence customers' intention either in purchasing or revisit behavior. 
Moreover, there is a positive medium significant relationship between signs, symbols and artifacts and customers' behavioral intention. From the result, it can be seen that the value of Pearson Correlation for signs, symbols and artifacts $(r=.365, p<0.05)$. According to Nguyen and LeBlanc (2002), clear direction, location and signs within a venue or any service setting will tend to influence the desirable mood among customers and positively correlates with quality of the service environment in that setting.

Table 4.2 Correlational and Reliability Analysis for Service Environment and Customers' Behavioral

\begin{tabular}{llcccccc}
\multicolumn{7}{c}{ Intention } \\
\hline No & Variables & Mean & SD & 1 & 2 & 3 & 4 \\
\hline 1 & Ambient Conditions & 4.50 & 0.43 & $(.874)$ & & & \\
2 & $\begin{array}{l}\text { Spatial, Layout and } \\
\text { Functionality }\end{array}$ & 4.43 & 0.40 & $.438^{* *}$ & $(.824)$ & & \\
3 & $\begin{array}{l}\text { Signs, Symbols and } \\
\text { Artifacts }\end{array}$ & 4.09 & 0.65 & $.382^{*+}$ & $.418^{*+}$ & $(.922)$ & \\
4 & $\begin{array}{l}\text { Customers' Behavioral } \\
\text { Intention }\end{array}$ & 4.42 & 0.47 & $.309^{*+}$ & $.358^{*+}$ & $.602^{*+}$ & $(.853)$ \\
\hline
\end{tabular}

\subsection{Hierarchical Regression Analyses}

Table 4.3 summarizes the results of the moderating effect of income on the relationship between service environment and customers' behavioral intention. Model 1 in the table reflects the direct relationship between service environment and customers' behavioral intention. Model 2 signifies the extent of additional variance explained when the moderator is included in the regression model. Meanwhile, model 3 highlights the interaction of the moderator variable with the independent variables and their relationship with the dependent variable. From the findings, Model 1 explains $19.8 \%$ of the variance. Model 2 explains $21.4 \%$ of variance and additionally $1.7 \%$ higher than variance in the Model 1 . Model 3 explains $25.5 \%$ of the variance, $4.1 \%$ increment in the variance explained. Model 3 shows significant $F$ change $(p<0.05, F=0.046)$. Referring to the Model 1 , the results indicate that three dimensions of independent variables; ambient conditions, spatial, layout and functionality and signs, symbols and artifacts are significant predictors of customers' behavioral intention. The value for ambient conditions is $(\beta=0.132, p<0.05)$, spatial, layout and functionality $(\beta=0.204, p<0.05)$ and signs, symbols and artifacts $(\beta=0.230, p<0.05)$.

Pertaining to the moderating effect of income on the relationship between service environment and customers' behavioral intention, Model 2 indicates the value of each categories of income. Lower middle income indicates $(\beta=0.007, p>0.05)$, middle income $(\beta=-$ $0.057, p>0.05)$, upper middle income $(\beta=-0.003, p>0.05)$ whereas high income $(\beta=0.100$, $p>0.05)$. With reference to the moderating effect of income on the relationship between service environment and customers' behavioral intention, the results can be seen in the Model 3 that highlights the interaction of the moderator variable with the independent variables and their relationship with the dependent variable. Pertaining to the moderating effect of lower middle income on the relationship between service environment and customers' behavioral intention, Model 3 signifies that the interaction between lower middle 
income is only significant with the first dimension of service environment (ambient conditions) whereby $(\beta=2.948, p<0.05)$ while the other two dimensions of service environment; namely spatial, layout and functionality and signs, symbols and artifacts are not significant in explaining the additional variance in the model.

Table 4.3: Summary of the Moderating Effect of Income on the Relationship between Service Environment and Customers' Behavioral Intention

\begin{tabular}{|c|c|c|c|}
\hline \multirow[t]{2}{*}{ Variables } & \multicolumn{3}{|c|}{ Customers' Behavioral Intention } \\
\hline & Model 1 Standard $\beta$ & Model 2 Standard $\beta$ & Model 3 Standard $\beta$ \\
\hline \multicolumn{4}{|l|}{ Independent Variables } \\
\hline Ambient Conditions (AC) & $0.132^{* *}$ & $0.103^{*}$ & -0.047 \\
\hline Spatial, Layout and Functionality (SLF) & $0.204^{* * *}$ & $-0.209^{* * *}$ & 0.499 \\
\hline Signs, Symbols and Artifacts (SSA) & $0.230^{* * *}$ & $0.240^{* * *}$ & 0.335 \\
\hline \multicolumn{4}{|l|}{ Moderating Variables } \\
\hline \multicolumn{4}{|l|}{ Income } \\
\hline Income 1 (Lower Middle Income) & & 0.007 & -1.148 \\
\hline Income 2 (Middle Income) & & -0.057 & 0.978 \\
\hline Income 3 (Upper Middle Income) & & -0.003 & 1.387 \\
\hline Income 4 (High Income) & & -0.100 & 0.518 \\
\hline \multicolumn{4}{|l|}{ Interaction } \\
\hline Income1 x Ambient Conditions & & & $2.948^{* * *}$ \\
\hline Income1 x Spatial, layout \& functionality & & & -1.487 \\
\hline Income 1 x Signs, Symbols and Artifacts & & & -0.416 \\
\hline Income2 x Ambient Conditions & & & 0.733 \\
\hline Income2 x Spatial, layout \& functionality & & & -1.977 \\
\hline Income3 x Spatial, layout \& functionality & & & -1.191 \\
\hline Income 3 x Signs, Symbols and Artifacts & & & -0.432 \\
\hline Income4 x Ambient Conditions & & & 0.644 \\
\hline Income4 x Spatial, layout \& functionality & & & -1.106 \\
\hline Income4 x Signs, Symbols and Artifacts & & & -0.056 \\
\hline $\mathrm{R}$ & 0.445 & 0.462 & 0.505 \\
\hline
\end{tabular}




\begin{tabular}{|l|l|l|l|}
\hline$R^{2}$ & 0.198 & 0.214 & 0.255 \\
\hline Adjusted $R^{2}$ & 0.191 & 0.918 & 0.218 \\
\hline F Change & 29.031 & 1.737 & 1.89 \\
\hline Significant F Change & $0.000^{* * *}$ & $0.141^{*}$ & $0.046^{* *}$ \\
\hline Durbin Watson & & & 1.961 \\
\hline
\end{tabular}

Notes: ${ }^{* *}$ significance at the 0.01 level; ${ }^{* *}$ significance at the 0.05 level; ${ }^{*}$ significance at the 0.1 level

Based on the findings, it can be concluded that only lower middle income level significantly moderate the relationship between ambient conditions and customers' behavioral intention and this hypothesis was supported by Tan (2011) stated individual preferences to make a living by considering the housing development elements offered by the developer is not excluding the perception from the lower income group that shows that either they satisfied or not with the benefits gained from purchasing the house. In addition, previous researcher also indicated that higher income groups are generally satisfied with their housing conditions and neighborhood (Vera-Toscano and Alteca-Amestoy, 2008). Thus, it can be concluded that only lower middle income significantly moderates the relationship between ambient conditions and customers' behavioral intention whereas the other level of income does not significantly moderate the relationship between service environment and customers' behavioral intention.

\subsection{Conclusions}

This study found that there is a significant relationship between service environment and customers' behavioral intention whereby II dimensions in service environment; ambient conditions, spatial, layout and functionality and signs, symbols and artifacts described that there is a positive relationship between service environment and customers' behavioral intention. However, the results revealed that only lower income was significantly moderates the relationship between service environment and customers' behavioral intention. Besides, there are several improvements need to be done in order to enhance the dimensions of service environment and customers' behavioral intention to help the property industries to achieve total customers' satisfaction regarding their housing development. In addition, it is recommended that the researcher should conduct a study in different types of property industries. Due to this research, the researcher has conducted at a well-known and wellestablished property organizations, which they already have their own customers' perceptions regarding their service environment provided to their customers. Besides, these property organizations also have their own branding which brings the positive affective response and evaluation from the customers. Hence, by conducting this kind of study at different types of property organizations, it is hope that the results will be more significant and the researcher can see the differences and able to recognize the most contributor factors 
that influence the customers' behavioral intention in purchasing a house or other property in the future.

\section{Acknowledgement}

The authors gratefully acknowledge Research Management Institute of Universiti Teknologi MARA for funding this research under the Grant of Research Intensive Faculty (RIF).

\section{References}

Baker, J., Grewal, D., and Parasuraman, A. (1994). The Influence of Store Environment on Quality Inferences and Store Image. Journal of the Academy of Marketing Science, 22(4), 328-339.

Bitner, M. J. (1992). Servicescapes: The Impact of Physical Surroundings on Customers and Employees. Journal of Marketing, 56 (2), 57-71.

Donovan, R. J. and Rossiter, J. R. (1982). Store Atmosphere: An Environmental Psychology Approach. Journal of Retailing, 58(1), 34-57.

Hair, J. F. J., Black, W.C., Babin, B. J., Anderson, R. E., and Tatham, R. L. (2006). Multivariate Data Analysis. $6^{\text {th }}$ Ed. New Jersey: Pearson Education, Inc.

Hanan, H. (2012). Every Day Practices and Experiential Urban Space. Asian Journal of Environment-Behaviour Studies. 8(3), 41-54.

Han, H. and Ryu, K. (2009). The Roles of the Physical Environment, Price Perception, and Customer Satisfaction in Determining Customer Loyalty in the Restaurant Industry. Journal of Hospitality and Tourism Research, 33(4), 487-510.

Hightower, R., Brady, M., and Baker, T. (2002). Investigating the Role of the Physical Environment in Hedonic Service Consumption: An Exploratory Study of Sporting Events. Journal of Retailing, 55(9), 697-707.

Kotler, P. (1973). Atmospherics as a Marketing Tool. Journal of Retailing, 49(4), 48-64.

Lovelock, C. H. and Wirtz, J. (2011). Services Marketing: People, Technology, Strategy. Pearson Publishing, Prentice Hall, New Jersey.

Mehrabian, A., and Russell, J. (1974). An Approach to Environmental Psychology. Massachusetts Institute of Technology, Cambridge, Massachusetts.

Ryu, K. (2005). Dinescape, Emotions, and Behavioral Intentions in Upscale Restaurants. Unpublished Doctoral Dissertation, Kansas State University, Manhattan, Kansas.

Ryu, K., and Jang, S. S. (2007). The Effect of Environmental Perceptions on Behavioral Intentions Through Emotions: The Case of Upscale Restaurants. Journal of Hospitality and Tourism Research, 31, 56-72.

Ryu, K., Lee, H. R., and Kim, W. G. (2012). The Influence of the Quality of the Physical Environment, Food, and Service on Restaurant Image, Customer Perceived Value Customer Satisfaction, and Behavioral Intentions. International Journal of Contemporary Hospitality Management, 24(2), 200-223.

Saruwono, M., et. al. (2012). Expressions ans Stylish Trends of Homeowners in Terrace Housing. Asian Journal of 
Environment-Behaviour Studies. 9(3), 47-58.

Syed Othman Thani, S.K., al. (2013). Amelioration of Urban Temperature through Landscape Design Approaching Hot-Humid Climate: A Review. Asian Journal of Environment-Behaviour Studies. 13(4), 13-528.

Vera-Toscano, E. and Ateca-Amestoy, V. (2008). The Relevance of Social Interactions on Housing Satisfaction. Social Indicators Research, 86, 257-274.

Walter, U., Edvardsson, B., and Ostrom, A. (2010). Drivers of Customers' Service Experiences: A Study in the Restaurant Industry. Managing Service Quality, 20(3), 236-258.

Wakefield, K. L. and Blodgett, J. G. (1996). The Effects of the Servicescape on Customers' behavioral Intentions in Leisure Service Setting. Journal of Services Marketing, 10(6), 45-61.

Zeithaml, V. A., Berry, L. L., and Parasuraman, A. (1996). The Behavioral Consequences of Service Quality. Journal of Marketing, 60, 31-46.

Zeithaml, V.A., Bitner, M. J. and Gremler, D.D. (2009). Services Marketing: Integrating Customer Focus Across The Firm. McGraw-Hill//rwin. Boston. 